This is an Accepted Manuscript of an article published by Taylor \& Francis in the Journal of Urban Design on 23Dec2019, available online: https://www.tandfonline.com/doi/full/10.1080/13574809.2019.1699399.

\title{
Sounds in the City: bridging the gaps from research to practice through soundscape workshops
}

\author{
Daniel Steele, Christine Kerrigan and Catherine Guastavino \\ McGill University, School of Information Studies (SIS) \& Centre for Interdisciplinary \\ Research in Music Media and Technology (CIRMMT), Montreal, Canada
}

Correspondence: daniel.steele@mail.mcgill.ca

\begin{abstract}
Sound has been relatively underrepresented in urban design considerations, especially the positive aspects of sound. Yet, a vast body of academic literature on urban soundscape could inform professionals. We report on workshops with iterative improvements, designed to bring soundscape research to practice. The two workshops were conducted as part of the Sounds in the City partnership, in collaboration with the City of Montreal. Different workshop formats are compared, and recommendations are furnished both in terms of promoting awareness of the role of urban sound and with the intent of informing similar knowledge mobilization activities for researchers in related environmental fields.
\end{abstract}

\section{Introduction}

Although sound can have a profound impact on the urban experience, it is an underrepresented component when it comes to its integration in everyday design practice. Poor sound environments can affect our sleep (WHO Regional Office for Europe 2009; Hume, Brink, and Basner 2012), increase our stress (Babisch 2000; Stansfeld and Matheson 2003), reduce our ability to pay attention (Clark and Sörqvist 2012), and have been linked to measurable reductions in years of healthy living (Babisch et al. 2010). Beyond health concerns, poor sound design wastes precious urban resources and space. For example, spaces can be rendered unusable due to the presence 
of excessive sound levels or distracting sound sources, even if the visual environment or amenities provided are otherwise suitable for a space's intended use. As a result, cities generally approach sound as a nuisance (i.e. noise), and focus on reducing the negative effects of sound pollution.

However, urban sound has also been approached by some as a positive resource. For example, adding music to a busy public space can promote lingering behaviour (Bild et al. 2016b; Aletta et al. 2016b) without affecting a space's perceived calmness (Steele, Bild, Tarlao, et al. 2019). In addition, urban sound can contribute to a sense of place, foster social interaction (Lavia et al. 2016), and restore our mental and attentional capacity (Alvarsson, Wiens, and Nilsson 2010; Payne and Guastavino 2013), addressing topics like well-being and quality of life.

An extensive body of academic literature on everyday sound perception has provided theoretical ground for a new multidisciplinary field of soundscape research that has potential implications for urban sound management by accounting for this sound-as-resource approach (Aletta, Kang, and Axelsson 2016; Botteldooren et al. 2013; 2015; Dubois, Guastavino, and Raimbault 2006; Kang 2006; Schulte-Fortkamp and Voigt 2012). Soundscape is defined as the acoustic environment as perceived, experienced, and/or understood by people or society, in context (ISO 12913-1: 2014 2014). While noise policies traditionally focus on quantitative descriptions of noise in terms of sound pressure levels (measured using decibels), the soundscape approach requires a qualitative understanding of urban sound (taking into account the perception, experience, and understanding from the definition), as well as integrating sound management with other technical factors within urban design (e.g. choice of materials). Soundscape researchers have identified the importance of accounting for the interrelatedness of sound with these other factors (e.g. faster traffic is likely louder traffic; Kang et al. 2016). The soundscape design strategy (Bild, Coler, et al. 2016) describes the integration of this knowledge, derived largely from academic research, to urban design projects.

To speak of perception, experience, and understanding requires considering space users, such as the activities that they are conducting while experiencing soundscapes (ibid). An integrated, user-centred planning process is already used by some urban designers (e.g. Healey 1997), but it is seldom applied when dealing specifically with sound considerations (Steele 2018) - noise is considered reactively rather than proactively. To that end, soundscape researchers have advocated integrating 
sound considerations in the early stages of design (Adams, Davies, and Bruce 2009; S. R. Payne, Davies, and Adams 2009; De Coensel et al. 2010; Brown and Muhar 2004), rather than waiting for noise problems to arise. However, there seem to be few actual design and planning examples to inform this paradigm shift.

This shift from reactive to proactive measures of dealing with urban sound necessitates collaboration between urban designers (and other built environment professionals), city officials, sound experts (soundscape researchers, acoustic consultants) and 'city users' (e.g. residents, public space users), as described by (Bild, Coler, et al. 2016). However, there is an acknowledged divide that exists between the two 'worlds' of practice and academia that have been highlighted extensively in the work of soundscape researchers (ibid) and landscape architects (Cerwen 2017). The research-practice gap has also been identified as one of the key challenges for soundscape research, based on interviews with ten early career researchers (Aletta and Xiao 2018). Traditional environmental noise management has been described as more a policy problem than a scientific problem, in that the harms of noise are well understood, but the ways to solve it are not (Kang 2006). In other words, siloed disciplinary approaches have failed to accurately inform policy and other decision-making processes about how to integrate the soundscape approach; more focused efforts are needed to mobilize research knowledge to practice through transdisciplinary collaborations bringing diverse experts to the same table to find new solutions.

This paper makes use of the concept of knowledge mobilization to describe the act of moving research knowledge to practice (i.e. 'bridging the gap'), defined as ' $\mathrm{t}] \mathrm{he}$ reciprocal and complementary flow and uptake of research knowledge between researchers, knowledge brokers and knowledge users-both within and beyond academia - in such a way that may benefit users and create positive impacts' (Government of Canada 2012).

Further, this research is described as transdisciplinary, which, as described by the National Science Foundation (NSF) as it applies to cities is,

\footnotetext{
Research practice that is explicitly concerned with drawing on and engaging with the expertise of actors outside of academic and research communities, with an emphasis on the co-production of knowledge with practitioners and social actors...(ACERE 2018, p. 11. and associated references)
}

This paper addresses two transdisciplinary knowledge mobilization activities performed 
by the Sounds in the City partnership to bridge this divide. A transdisciplinary, crosssector collaboration between university soundscape researchers, acoustic consultants, and the City of Montreal, Sounds in the City aims to address the gap between soundscape research and urban planning and design practices. Through outreach and knowledge co-creation activities the team brings research out of the university and into the world of practice. We report on the results and reflections of two workshops about soundscape for an audience of professionals including urban designers, planners, architects, sound professionals, and city officials. In the Review section, we cover the key concepts and literature supporting workshops as a tool for knowledge mobilization; this is followed by descriptions of the two workshops conducted. Results combine formal feedback from workshop attendees with reflections from the organizers showing how different workshop components contributed to the knowledge mobilization goal. The Discussion situates these findings within the research literature and presents nine outcomes and learnings. The Conclusion offers potential guidelines for researchers who would like to mobilize their environmental research to an urban design audience.

\section{Review}

Previous research on knowledge mobilization in urban design has identified a researchpractice gap, in general, from environmental research fields (including sound) to practice (e.g. Eliasson 2000; Lindqvist and Mattsson 1989). Pijpers van Esch (2015) reported that urban designers experienced difficulty with research uptake, and that while designers consult subject-matter experts on a regular basis, they rarely take the initiative to visit the scientific literature. Steele (2018) found that many designers do not regularly consult research because they find it difficult to apply directly to their projects, as the academic literature rarely resolved a question they had; however, among those who did consult academic literature, it was perceived to have high credibility. The perceived lack of applicability can be attributed to different work cultures between academia and practice. Taylor and Hurley (2016) suggest that researchers generally do not aim to make recommendations from their findings and instead let the findings speak for themselves, which leaves the problem of interpreting scientific findings to the practitioners.

Within the soundscape community, researchers describe ongoing challenges to mobilizing research. For example, Aletta and Xiao (2018) describe the 'applicability of 
the soundscape framework' (p. 8) as an ongoing issue in terms of determining appropriate scales and contexts for applying soundscape methods in practice. The same authors (ibid) also recognize a lack of supporting technologies for reproducing or simulating soundscapes, which could help represent this knowledge to designers. There is also the issue that while among sound research experts, there are terms with precise meaning (e.g. reverberation) to describe acoustic phenomena, there are many fewer terms to describe the associated sensory experiences (e.g. noisy). Raimbault and Dubois (2005) demonstrate how this lack of shared vocabulary extends to built environment professionals, such that there is little consensus on the meaning of even commonly used terms in practice, policy, as well as everyday life.

There are a few available resources aimed to compile information, disambiguate scientific discourse, and make soundscape research more accessible. For example, Kang et al. (2016) present a written F.A.Q. format on questions that professionals may have about soundscapes. However, an interview study with building designers (Cooper and Crisp 1984) revealed that design aids (i.e. guidebooks) alone were not likely to help designers extend their practice. Other recent research (Steele 2018) has identified people as information sources to be roughly equally as important as written sources for built environment professionals - thus a workshop model is being tested here as a tool for socializing soundscape concepts.

Workshops have been identified as an important knowledge mobilization tool for urban designers (e.g. Arciniegas and Janssen 2012; Geertman 2002), particularly in the context of planning support systems. Workshops can support an uptake of research lessons for practitioners in their everyday work, such as Badovinac (1997) who bridged policy with public health via workshops. Some studies have looked specifically at the activities conducted within workshops to understand their role as support aides. Gill et al. (2013) compared the free use of eight different visualization aides (e.g. plan views, images, models, 3D walkthroughs) for flood defence planning and found that, despite having little experience with 3D-aided decision-winge participants preferred and spent a predominant use of their time on the 3D visualization tools. In a series of participatory urban adaptation workshops, McEvoy et al. (2018) showed that different technology support tools had effects on learning, cooperation, participation, and even the final design product; however, group cooperation also relied partially on the effectiveness of facilitators. Transdisciplinary workshops can also serve as forums where participants can reflect on how to "translate" the rigorous technical language of academic literature 
for broader dissemination (Lusk 2018) and begin to co-create a shared vocabulary to speak about sound.

Recognizing the importance of workshops as a knowledge mobilization tool, they have also been tried in a limited fashion in the soundscape community (Xiao, Lavia, and Kang 2018). However, the lessons that have been articulated from these case studies are not always generalizable. Among the most synthetic of these, Cerwén, Kreutzfeldt, and Wingren (2017) put on a series of three workshops where they coidentified 22 "soundscape actions" that could be performed by landscape architects. Reflections from Fowler (2013) on teaching and hosting workshops for landscape architects highlighted the difficulty in incorporating sound as a parameter for design, but moreover highlighted the students' desire for soundscape representations that were comparable to their visual aids. The QUADMAP Project (Aspuru et al. 2016) provided recommendations for the selection, analysis, and management of quiet urban areas via a final report of actionable items to professionals. In addition to engineering interventions, the team recommended design interventions that impacted non-auditory perceptions (e.g. tree plantings that reduce the visual impact of a noise barrier). The EUfunded research project called SONORUS took a case study in each of four member cities and applied early sound considerations via recommendations from the researchers (Alves et al. 2015). The same group briefly detailed a series of workshops in each city, reported in the book Urban Sound Planning (Kropp, Forssén, and Estévez-Mauriz 2016).

This paper attempts to offer a more systematic analysis of how workshops could be used as a soundscape-oriented research mobilization tool, emphasizing the need to bring different stakeholders to the table to collaborate. We report on two workshops developed by the Sounds in the City team, as part of an iterative process, as tools aimed to mobilize knowledge about the role of urban sound in built environments for urban design practice. Given the demonstrated role of workshops as key tools in research mobilization, we borrowed from models on transdisciplinarity to develop a workshop that could serve as proof of concept for attempts to bridge academia and practice by bringing everyone to the design table as equals. We situate the research more broadly in terms of knowledge mobilization of an emerging environmental science (soundscape studies) and support the research by workshop participants' reports on the various activities. 


\section{Workshop descriptions}

Each of two workshops - one from November 2016 and one from May 2018 - covered a specific topic related to urban sound environments identified in collaboration with Montreal's planners. Workshop 1 focused on local pedestrianization projects while Workshop 2 focused on the identification and preservation of good-quality soundscapes, including parks, pedestrian zones, commercial zones, and a unique type of neighbourhood space in Montreal called ruelles vertes (green alleys). Extensive descriptions of the two workshops follow in the sections below.

\section{Workshop 1 -animating pedestrian zones in the sonic dimension}

Workshop 1 was held over two days at McGill University. It was open to the general public but was especially targeted for members of the soundscape research community, city officials, and practitioners of the built environment. The event was organized using four separate educational formats, illustrated in Figure 1 (See Steele et al. 2017 for more details on each educational format):

(1) site visits of three Montreal pedestrian zones under development;

(2) presentations on specific soundscape topics by researchers in the format "Academic presentations with soundscape 'building blocks" and overviews of the 3 site studies by practitioners who work for the city of Montreal; the content of the building blocks was: envisaged user activities, visualizations about sound using illustration, public art, sound installations, water features, and outdoor music.

(3) two laboratory demonstrations. The first demonstration used a multichannel array (using ambisonics, see Gerzon 1985) to present immersive soundscapes where "good" and "bad" sources could be added and removed. The second demonstration, presented over headphones, highlighted the perspective of a blind user navigating and narrating his daily route through the city (see Grond and Devos 2016); and

(4) collaborative design exercises with a focus on the three new pedestrian zones. Facilitated groups discussed considerations about soundscape in three different phases (Planning, Design, and Production), in addition to working with the previously described "building blocks". 


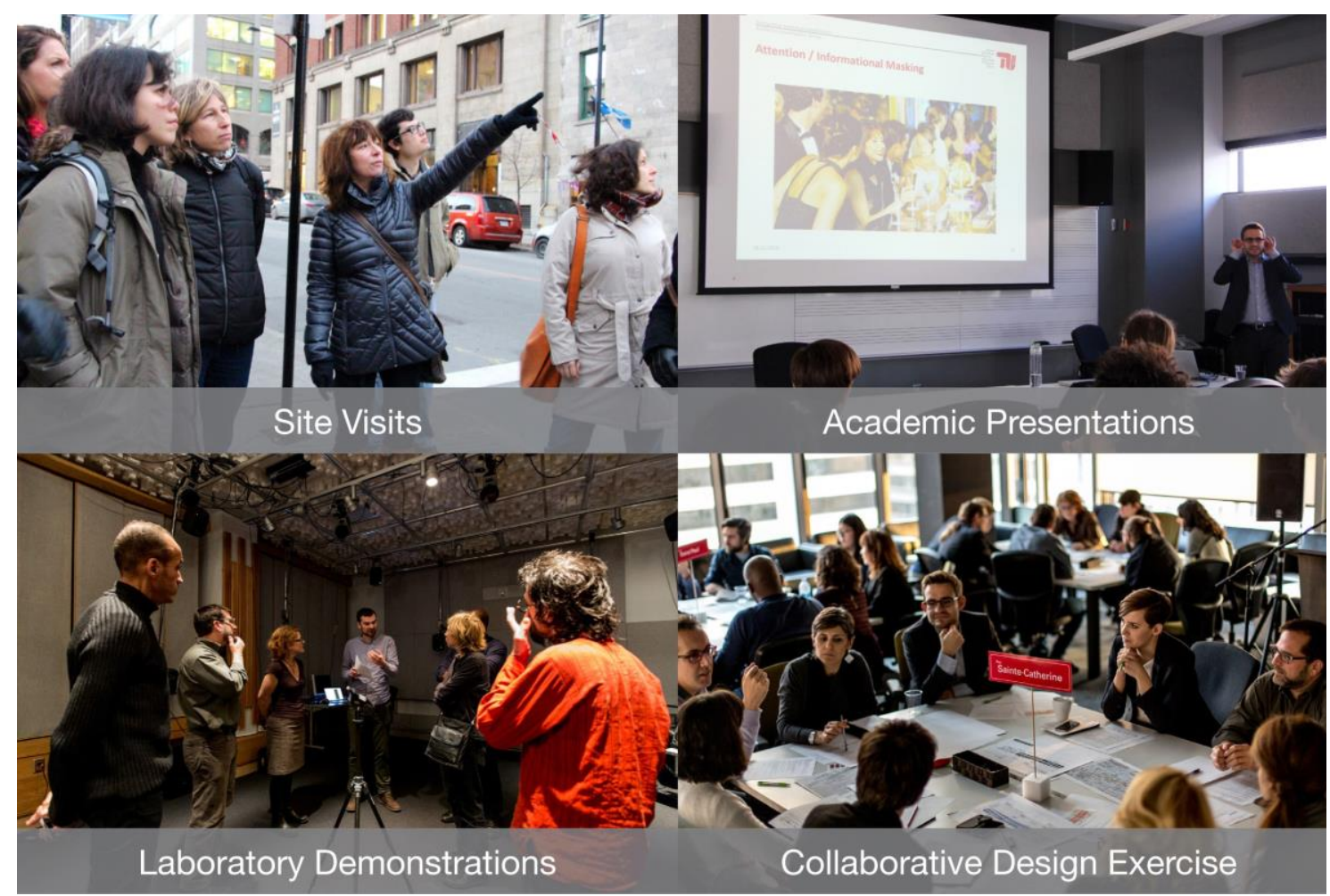

Figure 1: Workshop 1 description.

Motivation: why pedestrianization

Between 2015 and 2019, the City of Montreal planned upwards of 15 new pedestrian zones totalling up to 50 in the entire city $^{1}$. One of the pedestrian zones was to be a kilometres-long pedestrian-friendly route connecting the city's river to the mountain (Promenade fleuve-montagne). Based on initial discussions with municipal partners, pedestrianization was chosen as a pressing and relevant topic for a workshop. Focusing on pedestrianization also provided an opportunity to explain soundscape concepts; for example, when the main sources of mechanical sound are removed from an environment (e.g. noise from traffic), this provides the opportunity to cultivate 'positive' sounds and avoid 'awkward silences' in the spaces.

${ }^{1}$ https://ville.montreal.qc.ca/ruespietonnes/ 


\section{Workshop 2 - What role does sound play in the design of our public spaces? How can we identify and preserve good-quality urban sound environments?}

Workshop 2 was held over a single day at the Institute du Tourisme et d'Hôtellerie du Québec (Institute of Tourism and Hospitality of Quebec, ITHQ). The workshop (see Figure 2) entailed:

(1) a soundwalk in the surrounding neighbourhood;

(2) presentations;

(3) collaborative design exercises with multidisciplinary teams; and

(4) a full-group roundtable discussion.

Motivation: why focus on identifying and preserving sound environments?

The Sounds in the City municipal partners had identified difficulties in using Montreal's existing noise regulations in certain types of spaces. The one-size-fits-all noise level restrictions, while appropriate for some typical street-side residential areas, were considered not strict enough to protect users of spaces like public parks and Montreal's ruelles vertes (shared back alleys, which have been collectively redesigned by local residents, in collaboration with the eco-district of the borough). In these ruelles vertes, spaces were often appropriated by residents for leisure use, especially for children; however, these spaces also often contain the HVAC units for residents' bedrooms HVAC units that are required by regulation to be installed on the alley side. Therefore, these spaces were identified for their relevance for soundscape methods.

\section{Soundwalk}

The soundwalk consisted of an (accessible) walking tour with multiple pre-planned stopping points. At each point, participants answered six short questions about the sound environment in a journal (see ). Following the writing activity, the soundwalk leaders (author DS; Romain Dumoulin) spoke briefly about concepts and research that was relevant to that particular environment. In total, there were 12 stops representing different sound environments, including a ruelle verte, two alleyways (one in a residential area and the other in a commercial area), a large park, a pedestrian zone, and a commercial area. The soundwalk lasted 2.5 hours. The participants were divided into two groups: a French-led and an English-led group. 


\begin{tabular}{|c|l|}
\hline 1 & $\begin{array}{l}\text { Was there a transition in the soundscape between our last stop and here? } \\
\text { How would you describe it? Was there anything specific that you noticed? }\end{array}$ \\
\hline 2 & What do you think this space is used for? \\
\hline 3 & What is your general impression of the soundscape? \\
\hline 4 & $\begin{array}{l}\text { Please list the sounds you hear } \\
\text { a. Circle the sounds you hear that are appropriate for the function of the } \\
\text { space (that you mentioned above) } \\
\text { b. Strike through the ones that are inappropriate for the function of the } \\
\text { space }\end{array}$ \\
\hline 5 & $\begin{array}{l}\text { What sounds would you like to hear at this stop? } \\
\text { Do you think others would feel the same about this space as you do? (An } \\
\text { elderly person? A child? A blind person? A teen? Etc.) }\end{array}$ \\
\hline
\end{tabular}

Table 1: Soundwalk journal activity, to be completed at each stopping point

\section{Presentations}

Workshop 2 presentations were similar to those from Workshop 1 in that sound experts were asked to present content that would be interesting and relevant for design professionals. The presentation themes were: an introduction to urban sound environments; vulnerable groups and soundscapes; different sound conceptualizations; and a review of existing regulations around quiet zones worldwide. Presentations were structured to be informative and to seed the discussions for the collaborative design exercise.

\section{Collaborative design exercise}

Workshop 2 design exercises were organized to build on the experience gained from Workshop 1. Having incorporated feedback from the facilitators of the collaborative design exercise in Workshop 1 (detailed in the Results section), the study areas focused less on specific project sites being developed by the city, and instead on types of sites (e.g. park, commercial street, ruelle verte). Discussions were supported again by worksheets, but also by line drawings (see Figure 2d) designed to represent the spaces under discussion, rather than maps and photos. Each group was instructed to choose 2 of 4 available site types and to go through the worksheet for each, using their journal entries from the soundwalk to inform discussions. Both sound and visual considerations and expertise were equally important throughout the exercises. Finally, groups presented a 5-minute summary of their discussions to the other groups. A break 


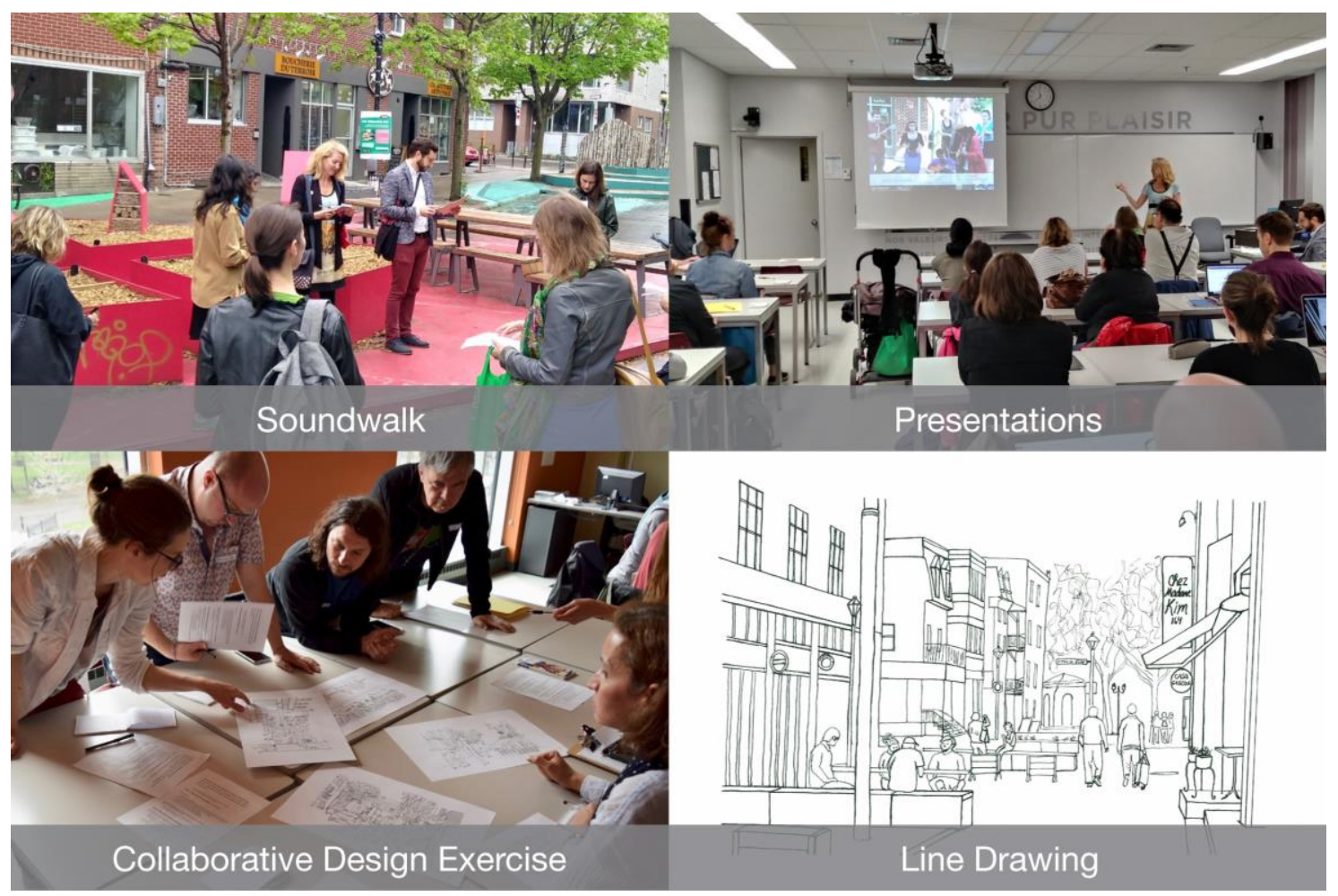

Figure 2: Workshop 2 descriptions.

immediately followed while facilitators convened and summarized the overarching themes, which were again presented to all participants to seed the large-group discussion.

\section{Large group discussion}

A multidisciplinary designer (author $\mathrm{CK}$ ) led a final closing discussion on theme areas pertaining to long- and short-term steps that professionals can take to identify and protect good-quality urban soundscapes. Insights were gathered from participants about how they wish to learn about and use soundscape knowledge and practical steps were discussed about creating a network of soundscape-informed colleagues. The final point about the importance of creating professional networks is supported by the finding that professionals in smaller organizations sometimes use their personal networks of people with similar experiences to gather information about unknowns (Steele 2018).

The workshops are incorporated into an iterative research process. Workshop 1 was informed by early results from, for example, the finding that urban designers feel they are expected to integrate information across design factors (e.g. water, materials) to make a coherent design (ibid). In this context, workshop exercises were structured to 
support dialogue about the interaction of sound with other factors and serve as a collaborative design exercise. Presentations and the interactive activities were piloted with design colleagues. Workshop 2 further built on lessons learned from Workshop 1.

\section{Results}

\section{Audience and survey}

Workshop 1 comprised 61 registered participants, including organizers, while for Workshop 2, capacity was strictly limited to 40 (of 54 who attempted registration), including organizers. In Workshop 1, soundscape and design professionals joined from Montréal, Germany, the Netherlands, and the UK; Workshop 2 was more targeted to local and Quebec professionals.

Following each workshop, participants were contacted via email to provide feedback using an online survey. The survey included general questions about the way participants use and think about sound in their everyday work, numerical ratings from workshop participants of individual sessions (formats), and free-format responses describing what participants liked and did not like about each format. These results were supported by reflections from the workshop organizers based on notes and recordings from the events. Seventeen participants responded to the survey for each workshop; however, response rates for individual sessions may be slightly lower in the case where a participant did not attend an individual session.

Participants were from the private, public, and academic sectors. For the first workshop, among those who responded to this question, $29 \%$ were from the public sector, $29 \%$ from the private sector, and $18 \%$ from academia; in the second $35 \%$ were from the public sector and 53\% were from the private sector (two did not indicate a sector).

\section{Results of participant feedback by format}

Participants were asked three standard questions about sound, shown in Table 2. Note that these questions were posed only after the event. These were followed by ratings of each of the workshop formats; to standardize across the workshops, the scores 'I found the session useful' and 'I found the session interesting' from Workshop 1 were averaged 


\begin{tabular}{|l|l|}
\hline 1 & "I am sensitive to sound in my daily environment" \\
\hline 2 & "I consider sound in my work practice" \\
\hline 3 & "this event influenced the way I consider sound in public spaces" \\
\hline
\end{tabular}

Table 2: Three questions for participants at each workshop

together for a single score. They were compared against the question 'I found the session informative' from Workshop 2. Figure 3 compiles these results.

Results indicate that the highest rated format was laboratory demonstrations, scoring 4.81 of 5 , compared to the next closest rating of the soundwalks at 4.54 of 5 . The lowest scoring format was the collaborative design exercise of Workshop 1, with a score of 4.04; however, concerns about the structure of these were addressed (covered in the Discussion), such that the score for the similar session from Workshop 2 recovered to 4.53. All other scores that were comparable between workshops showed modest rises.

The free-response feedback from participants about each of the formats provides a more detailed understanding of how each was evaluated. Participants indicated what

Workshop Scores (Workshop \#, number of respondents)

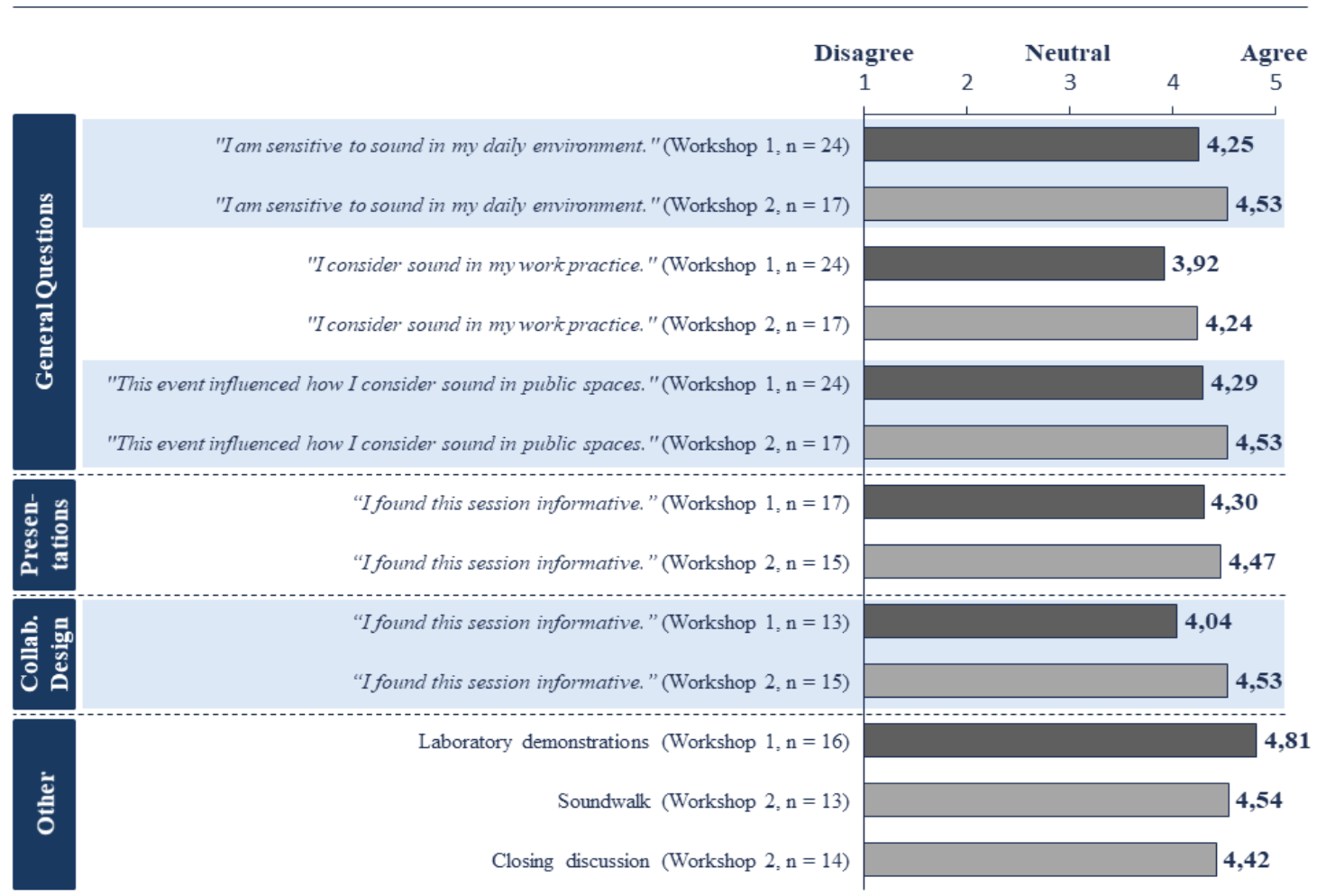

Figure 3: workshop scores by format 
they liked about each format and what they thought could be improved. Their comments have been summarized and compiled in a 'pros and cons' analysis in Table 3.

As demonstrated in the table, the pros of the traditional presentation format were offset by a long list of cons, centred particularly on concerns about the quality of the presentation and interactivity of the speaker. The laboratory demonstrations and soundwalk were both highly rated and appeared to be appreciated most for their

\begin{tabular}{|c|c|c|}
\hline Format & Pros & Cons \\
\hline Presentations & $\begin{array}{l}\text { - Ability to cover broad topics } \\
\text { - Instructive for unknown topics } \\
\text { - Able to seed discussions } \\
\text { - Applicability (when case studies } \\
\text { effectively presented) }\end{array}$ & $\begin{array}{l}\text { - Lack of connection to speaker } \\
\text { - Low interactivity } \\
\text { - Lack of immersive experience } \\
\text { - Can be perceived as too boring, } \\
\text { focused, detailed, or "academic" }\end{array}$ \\
\hline $\begin{array}{l}\text { Collaborative } \\
\text { Design } \\
\text { Exercises }\end{array}$ & $\begin{array}{l}\text { - Encourage interactions with } \\
\text { experts } \\
\text { - Promote interdisciplinary } \\
\text { thinking and problem solving } \\
\text { - Facilitate addressing local } \\
\text { concerns } \\
\text { - Facilitate applying knowledge } \\
\text { from other sources }\end{array}$ & $\begin{array}{l}\text { - Require introduction and } \\
\text { explanation of activity to each } \\
\text { member } \\
\text { - Case discussed needs to be } \\
\text { sufficiently abstract to avoid } \\
\text { discussing unrelated project } \\
\text { constraints } \\
\text { Discussions require attentive } \\
\text { facilitation to stay on topic }\end{array}$ \\
\hline $\begin{array}{l}\text { Laboratory } \\
\text { demonstrations }\end{array}$ & $\begin{array}{l}\text { - Immersive learning benefits and } \\
\text { experience } \\
\text { - Learning directly from experts } \\
\text { - Live application of presented } \\
\text { concepts } \\
\text { - Can be striking } \\
\text { - Shows tangible design potential }\end{array}$ & $\begin{array}{l}\text { Difficult to quickly adjust content } \\
\text { of lab demos to questions or } \\
\text { emergent topics }\end{array}$ \\
\hline Soundwalk & $\begin{array}{l}\text { - Immersive learning benefits } \\
\text { - Promote awareness of multiple, } \\
\text { diverse soundscapes } \\
\text { - Facilitates active listening } \\
\text { - Demonstrates how urban design } \\
\text { influences soundscape and vice } \\
\text { versa } \\
\text { - Emphasizes connection between } \\
\text { user-soundscape-activity } \\
\text { - Allows live expert commentary } \\
\text { with interactive questions }\end{array}$ & $\begin{array}{l}\text { - Requires intense pre-planning of } \\
\text { route } \\
\text { - Weather-dependent }\end{array}$ \\
\hline $\begin{array}{l}\text { Large group } \\
\text { facilitated } \\
\text { discussion }\end{array}$ & $\begin{array}{l}\text { - Encourages balance of speakers } \\
\text { - Encourages open, live } \\
\text { questioning }\end{array}$ & $\begin{array}{l}\text { - Difficulty in balancing time- } \\
\text { management and completeness }\end{array}$ \\
\hline
\end{tabular}

Table 3: Summarized pros and cons of each workshop format as derived from freeformat descriptions of what workshop participants liked and did not like about each format. 
immersive component. The collaborative design exercises had a similarly long list of pros, which offered the opportunity for participants to synthetically test and exchange their ideas with professionals from various domains. However, compared to the demonstrations, the design exercises required preparation of participants (i.e. through presentations) in order to ensure all participants were 'on the same page' for the activity.

From the collaborative design exercises, fruitful discussions on representations of soundscape brought forth ideas for supporting the multi-stakeholder conversations. For example, designers and soundscape researchers iterated ideas for spaces that could be appropriate for water features, such as articulating how they could simultaneously mask traffic noise, create a sound landmark, and provide a setting that evoked nature. One of the soundscape experts with training in architecture captured some of these iterated ideas discussed through illustration. The images captured representations of sound in the context of the morphology, the activities, and the character of the sources. One of these images is reproduced in Figure 4. Other examples of proposed interventions that arose from the collaborative design exercises were the idea for reducing a two-way street on a steep slope to a downhill-only one-way street to reduce the sound of motors straining to climb the hill along the pedestrian zone. Another group discussed the types of materials that could prevent sound transmission: initially professionals considered an inflatable structure to block construction from view in a commercial street, but through exchanges with sound experts realized that construction noise would pass through and interfere with the planned activities. A joint debriefing from the table leaders brought to light how groups who were discussing projects that were already mature in their planning (primarily found in Workshop 1) had a more difficult time proposing creative solutions because of the constraints posed by existing decisions already made in the project planning.

\section{Discussion}

This section first situates the results described above within the presented literature, then follows with generalized learnings stemming from our experiences with these workshops, organized from outcomes of the workshops to learnings about knowledge mobilization. 


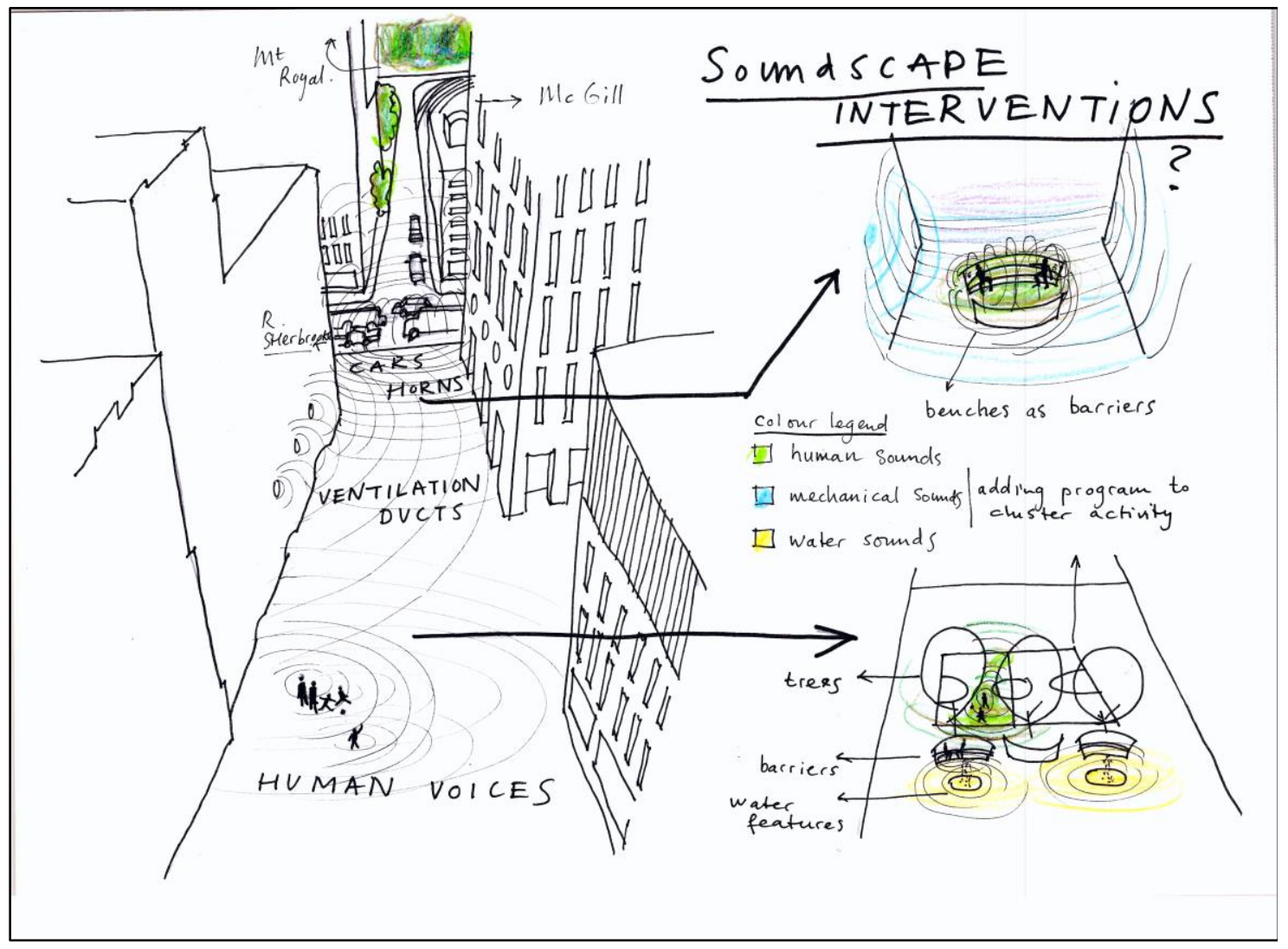

Figure 4: Supportive illustration of multi-stakeholder soundscape concepts. Image credit: Martijn Lugten

Feedback from participants confirmed the initial expectation that workshops function as a knowledge mobilization tool (Arciniegas and Janssen 2012; Geertman 2002). Our participants strongly reported that these workshops influenced the way they consider sound in their work, corroborating Badovinac (1997), and expressed interest in future events. Different workshop formats clearly offered different benefits that need to be balanced with the drawbacks.

In addition, while McEvoy et al. (2018) found that quality of facilitation was a key variable in the success of group design work, we found that the selection of the design case played a similarly crucial role. As previously mentioned, the collaborative design exercises in Workshop 2 were rated higher than in Workshop 1. For Workshop 1, actual sites were used as case studies to illustrate and provoke discussion about soundscape concepts. City employees working on the projects were also involved in the discussions and some projects were at an advanced stage in the planning process. In Workshop 2, hypothetical sites were used (e.g. a park, a pedestrian street, etc.) and 
represented by more abstract hand-drawn line illustrations. The workshop organizers felt that the Workshop 2 collaborative design exercises were more productive from a creative and synthetic standpoint, and thus more highly rated, for a few reasons: namely that participants could focus on using the exercise for discussing soundscape interventions rather than being side-tracked by logistical constraints due to the current state of the project; they did not have to worry about resources already being committed to interventions that conflicted with newly proposed ideas; and most importantly, those who were working on the real project in Workshop 1 felt protective of the decisions that had already been made, limiting the freedom of participants to brainstorm new possibilities.

In addition to the practical implication for future workshops, the result supports the importance of incorporating early-stage sound planning, which has been advocated by a number of soundscape researchers (Lavia et al. 2016; De Coensel et al. 2010; Brown and Muhar 2004). Sound implications should be considered early in the planning process, before practical limitations arising in design and production phases prevent proactive discussions about soundscape.

The workshops were also designed to be sensitive to the various needs and realities of professionals' work. Having designed the sessions with the knowledge that designers report a responsibility to integrate all factors and make a coherent plan (Steele 2018), the collaborative design exercises were created to allow the designers to consider sound in the context of their everyday work. This may explain why participants appreciated the 'interdisciplinary problem solving.'

Another point of discussion centres on the high score of the laboratory demos. We draw on the finding (ibid) showing that practitioners generally perceive academic research as having high credibility but lacking transferability to practical problems (i.e. applicability). The laboratory demonstration of the present study capitalizes on the credibility of the researchers by inviting designers into the laboratory space. However, the demonstrations also addressed the applicability problem by offering participants the opportunity to hear live explanations accompanied by tailored examples, and to ask questions about the relevance of the demonstrations to their work. The laboratory demonstrations also emphasized the importance of human experience over the measurement of sound levels (Schulte-Fortkamp and Voigt 2012; ISO 12913-1: 2014 2014). Participants were able to hear how measured decibel levels did not predict evaluations of environmental sounds (like annoyance), and instead the auditory 
experience and meanings associated with the sounds played a more crucial role in determining their appropriateness for the space.

The remainder of this section will be an enumeration of the above findings structured in terms of outcomes and learnings on knowledge mobilization.

\section{Outcomes:}

1. Participants were able to "see" sound and its role in the urban environment:

a. Participants were made aware that sound is continually present and that its presence is part of what makes an urban space characteristic.

b. Participants were made aware of the relationship that sound has to space users and patterns of behaviour - poor sound environments can make it difficult to use a space for intended programs while "good" sound environments can support intended programs and reflect positively on the space and/or the city.

2. Participants felt empowered to embrace and champion positive sound environments (using a soundscape design strategy) instead of relying on a noise-only approach.

a. Professionals of the built environment have the power to influence soundscapes. Designs, plans, and decisions can influence the soundscape in relation to Outcome 1, even if not directly related to sound (e.g. traffic diversions can greatly influence the soundscape.)

b. These workshops presented an opportunity to learn about the benefits of discussing and speaking with stakeholders. These discussions can elaborate on the complex relationships between the users' intended activities, desired sound environments, and sound sources.

3. Built environment professionals and sound experts alike were able to share vocabulary and conceptualizations about urban sound.

\section{Learnings on knowledge mobilization activities:}

4. Workshops are confirmed as a forum where the process of creating a common understanding of transdisciplinary issues could begin.

5. Workshops are relationship builders: organizers should not expect major new solutions to necessarily emerge from workshops; however, the expectation should be to form connections between new communities and professionals, engage new discussions, and help professionals to realize the extent of possible sound opportunities that can be considered for future projects.

6. Workshops may help reveal and validate practitioner assumptions: iterative discussions with experts can make sometimes implicit knowledge explicit. For example, 
convening discussion starting from anecdotal knowledge that fountains encourage lingering behaviour could lead to purposeful uses of water sounds.

7. Hypothetical scenarios elicit more creative solutions: it is easier to brainstorm creative soundscape solutions when the focus is not on actual projects that are already in the design or development phase to avoid participants from being constrained by politics and decisions that have already been made.

8. Exercises should blend real-world immersion with scenarios: participants were most appreciative of workshop formats that prioritized immersive (e.g. listening to soundscapes $v$. listening to a presentation) and interactive (i.e. the ability to ask questions as they arose) components. The soundwalk and laboratory demonstrations were the most effective of these activities.

9. Attendees should represent a diverse mix of stakeholders: attention must be paid to the professional backgrounds of participants when structuring activities to ensure that the expertise of each can contribute productively to the activity and discussions. If one type of expertise is overly represented (including sound), the discussions may not be as fruitful and productive.

\section{Conclusions and recommendations}

Beyond the learnings presented above, there may not be one single workshop format that incorporates all the key needs. Therefore, we recommend using a mixture of formats and carefully considering the appropriate format for each activity. For example, the soundwalk is an effective immersive format, but has significant logistical constraints (weather dependent, extensive route planning, need for small groups, etc.). Collaborative design exercises require introductions and facilitation, but given enough time, can be very effective in socializing concepts and 'bouncing' ideas off of a diverse group of professionals. Group exercises also equalize the various stakeholder expertise at the table, emphasizing the knowledge and experience that each participant brings to the issues at hand.

Building on an understanding of the role of human networks in information sharing (e.g. Steele 2018), these workshops also present practical networking opportunities for participants. Workshops should include icebreakers and ample breaks for informal discussions and networking. 
Our experience also suggests the importance of visual aids and demonstrations that go beyond providing only measurements in decibels (e.g. a noise map). Visual aids and demonstrations give a sense of the environment and make sound considerations more tangible. Participants often drew on and pointed to the provided visual materials for reference.

Given that urban designers engage in similar information behaviour and use of research for noise and other environmental factors (e.g. daylight and ventilation; Pijpers van Esch 2015), the present findings and recommendations for knowledge mobilization are likely to generalize beyond the urban sound topic.

A practical recommendation is to consider offering continuing education certificates, which could help employers allow their employees to attend workshops. Based on our experience with the Sounds in the City partnership, we have observed that job turnover among city employees can be high. We suggest that it is important to work with multiple advocates within various city departments in order to maintain momentum and relationships for knowledge mobilization activities.

\section{Future work}

These workshops have informed ongoing knowledge mobilization activities within and beyond Sounds in the City, including soundwalks for the general public (e.g. UQAM's Coeur des Sciences, Montreal's Botanical Gardens, and a local Montreal school), meetings with citizen groups, and new site studies around Montreal. These events have promoted discussions about sound(scapes) between researchers, designers, city makers, and city users. We plan to use the best practices and lessons learned from workshops to develop further training for urban designers around emergent topics of interest (e.g. high-rise development, management of large-scale outdoor events, etc.).

Other opportunities for future work are real-time interactive soundscape simulations that make it easier to respond to questions and suggestions. In addition, we can further support the connection between soundscape and popular, emerging models of participatory design and planning. Integrating soundscape within these models could help propel knowledge mobilization by using trusted frameworks. 


\section{Acknowledgments}

The project is supported by research grants from Canada's SSHRC (Social Sciences and Humanities Research Council) \# 430-2016-01198 (Insight Development Grant) and \# 8902017-0065 (Partnership Development Grant) to Catherine Guastavino (P.I.).

The authors would like to thank Romain Dumoulin, Florian Grond, Kaisa Tikkanen and the Goethe-Institut Montreal, Annelies Bockstael (Co-P.I., PDGrant), Cynthia Tarlao, Martijn Lugten, Johannes Scherzer, and all of the workshop presenters for their efforts in making the workshops possible; Edda Bild and Katharine Lusk for assistance with the theoretical framework and editing; and CIRMMT, SIS and the ITHQ for generous use of their facilities. The authors would like to thank Initiative on Cities at Boston University for their input.

\section{Funding}

The project is supported by research grants from Canada's SSHRC (Social Sciences and Humanities Research Council) \# 430-2016-01198 (Insight Development Grant) and \# 890-2017-0065 (Partnership Development Grant) to Catherine Guastavino (P.I.).

\section{ORCID}

Daniel Steele http://orcid.org/0000-0002-5673-755X

Christine Kerrigan http://orcid.org/0000-0001-6736-8414

Catherine Guastavino http://orcid.org/0000-0002-5750-2015

\section{References}

Adams, Mags, William Davies, and Neil Bruce. 2009. "Soundscapes: An Urban Planning Process Map.” In Proceedings of Internoise 2009. Ottawa, Canada: INCE. http://usir.salford.ac.uk/2465/.

Advisory Committee for Environmental Research and Education. 2018. "Sustainable Urban Systems: Articulating a Long-Term Convergence Research Agenda. A Report from the NSF Advisory Committee for Environmental Research and Education. Prepared by the Sustainable Urban Systems Subcommittee." Accessed 10 October 2019. https://www.nsf.gov/ere/ereweb/ac-ere/sustainableurban-systems.pdf

Aletta, Francesco, Jian Kang, and Östen Axelsson. 2016. "Soundscape Descriptors and a Conceptual Framework for Developing Predictive Soundscape Models.” 
Landscape and Urban Planning 149 (May): 65-74.

https://doi.org/10.1016/j.landurbplan.2016.02.001

Aletta, Francesco, Federica Lepore, Eirini Kostara-Konstantinou, Jian Kang, and Arianna Astolfi. 2016. “An Experimental Study on the Influence of Soundscapes on People's Behaviour in an Open Public Space.” Applied Sciences 6 (10): 276. https://doi.org/10.3390/app6100276

Aletta, Francesco, and Jieling Xiao. 2018. "What Are the Current Priorities and Challenges for (Urban) Soundscape Research?” Challenges 9 (1): 16. https://doi.org/10.3390/challe9010016

Alvarsson, Jesper, Stefan Wiens, and Mats Nilsson. 2010. "Stress Recovery during Exposure to Nature Sound and Environmental Noise.” International Journal of Environmental Research and Public Health 7 (3): 1036-46. https://dx.doi.org/10.3390/ijerph7031036

Alves, Sonia, Laura Estévez-Mauriz, Francesco Aletta, Gemma Echevarria-Sanchez, and Virginia Puyana Romero. 2015. "Towards the Integration of Urban Sound Planning in Urban Development Processes: The Study of Four Test Sites within the SONORUS Project." Noise Mapping 2 (1). https://doi.org/10.1515/noise2015-0005

Arciniegas, Gustavo, and Ron Janssen. 2012. "Spatial Decision Support for Collaborative Land Use Planning Workshops." Landscape and Urban Planning 107 (3): 332-42. https://doi.org/10.1016/j.landurbplan.2012.06.004

Aspuru, Itziar, Igone García, Karmele Herranz, and Alvaro Santander. 2016. “CITISENSE: Methods and Tools for Empowering Citizens to Observe Acoustic Comfort in Outdoor Public Spaces." Noise Mapping 3 (1). https://doi.org/10.1515/noise-2016-0003

Babisch, Wolfgang, Guillaume Dutilleux, Marco Paviotti, Anna Backman, Balazs Gergely, Brian McManus, Jose Luis Bento Coelho, et al. 2010. Good Practice Guide on Noise Exposure and Potential Health Effects. Copenhagen: European Environment Agency.

Babisch, Wolfgang. 2000. "Traffic Noise and Cardiovascular Disease: Epidemiological Review and Synthesis." Noise and Health 2 (8): 9.

Badovinac, Kimberly. 1997. "Policy Advocacy for Public Health Practitioners: Workshops on Policy Change.” Public Health Nursing 14 (5): 280-85. https://doi.org/10.1111/j.1525-1446.1997.tb00376.x 
Bild, Edda, Matt Coler, Karin Pfeffer, and Luca Bertolini. 2016. "Considering Sound in Planning and Designing Public Spaces: A Review of Theory and Applications and a Proposed Framework for Integrating Research and Practice." Journal of Planning Literature 31 (4): 419-34. https://doi.org/10.1177/0885412216662001

Bild, Edda, Daniel Steele, Cynthia Tarlao, Catherine Guastavino, and Matt Coler. 2016.

"Sharing Music in Public Spaces: Social Insights from the Musikiosk Project (Montreal, CA)." In INTER-NOISE and NOISE-CON Congress and Conference Proceedings, 253:3657-66. Institute of Noise Control Engineering.

Botteldooren, Dick, Tjeerd Andringa, Itziar Aspuru, Lex Brown, Danièle Dubois,

Catherine Guastavino, Jian Kang, Catherine Lavandier, Mats Nilsson, and Anna Preis. 2015. "From Sonic Environment to Soundscape." In Soundscape and the Built Environment, edited by Jian Kang and Brigitte Schulte-Fortkamp, 17-42. Boca Raton: CRC Press.

Botteldooren, Dick, Tjeerd Andringa, Itziar Aspuru, Lex Brown, Daniele Dubois, Catherine Guastavino, Catherine Lavandier, Mats Nilsson, and Anna Preis. 2013. "Soundscape for European Cities and Landscape: Understanding and Exchanging.” In Soundscape of European Cities and Landscapes, edited by J.

Kang, K. Chourmouziadou, K. Sakantamis, B. Wang, and Y. Hao, 36-43.

Oxford, UK: Soundscape-COST.

Brown, Lex, and Andreas Muhar. 2004. "An Approach to the Acoustic Design of Outdoor Space.” Journal of Environmental Planning and Management 47 (6): 827-42. https://doi.org/10.1080/0964056042000284857

Cerwen, Gunnar. 2017. "Sound in Landscape Architecture: A Soundscape Approach to Noise.” PhD diss., Swedish University of Agricultural Sciences, Department of Landscape Architecture, Planning and Management.

Cerwén, Gunnar, Jacob Kreutzfeldt, and Carola Wingren. 2017. "Soundscape Actions:

A Tool for Noise Treatment Based on Three Workshops in Landscape

Architecture." Frontiers of Architectural Research 6 (4): 504-18.

https://doi.org/10.1016/j.foar.2017.10.002

Clark, Charlotte, and Patrik Sörqvist. 2012. “A 3 Year Update on the Influence of Noise on Performance and Behavior." Noise and Health 14 (61): 292. https://doi.org/10.4103/1463-1741.104896 
Cooper, Ian, and V. H. C. Crisp. 1984. "Barriers to the Exploitation of Daylighting in Building Design: U.K. Experience.” Energy and Buildings 6 (2): 127-32. https://doi.org/10.1016/0378-7788(84)90067-7

De Coensel, Bert, Annelies Bockstael, Luc Dekoninck, Dick Botteldooren, Brigitte Schulte-Fortkamp, Jian Kang, and Mats Nilsson. 2010. "The Soundscape Approach for Early Stage Urban Planning: A Case Study.” In Proc. Inter Noise, (Lisbon, Portugal).

Dubois, Danièle, Catherine Guastavino, and Manon Raimbault. 2006. "A Cognitive Approach to Urban Soundscapes: Using Verbal Data to Access Everyday Life Auditory Categories." Acta Acustica United with Acustica 92 (6): 865-74.

Eliasson, Ingegärd. 2000. "The Use of Climate Knowledge in Urban Planning." Landscape and Urban Planning 48 (1-2): 31-44. https://doi.org/10.1016/S01692046(00)00034-7

Fowler, Michael. 2013. "Soundscape as a Design Strategy for Landscape Architectural Praxis.” Design Studies 34 (1): 111-28. https://doi.org/10.1016/j.destud.2012.06.001

Geertman, Stan. 2002. "Participatory Planning and GIS: A PSS to Bridge the Gap." Environment and Planning B: Planning and Design 29 (1): 21-35. https://doi.org/10.1068/b2760

Gerzon, Michael. 1985. "Ambisonics in Multichannel Broadcasting and Video." Journal of the Audio Engineering Society 33 (11): 859-71.

Gill, Lewis, Eckart Lange, Ed Morgan, and Daniela Romano. 2013. “An Analysis of Usage of Different Types of Visualisation Media within a Collaborative Planning Workshop Environment." Environment and Planning B: Planning and Design 40 (4): 742-54. https://doi.org/10.1068/b38049

Government of Canada, Social Sciences and Humanities Research Council. 2012. "Social Sciences and Humanities Research Council: Definitions of Terms." Accessed 10 October 2019. http://www.sshrc-crsh.gc.ca/fundingfinancement/programs-programmes/definitions-eng.aspx

Grond, Florian, and Piet Devos. 2016. "Sonic Boundary Objects: Negotiating Disability, Technology and Simulation.” Digital Creativity 27 (4): 334-46.

https://doi.org/10.1080/14626268.2016.1250012

Healey, Patsy. 1997. Collaborative Planning: Shaping Places in Fragmented Societies. London: Macmillan International Higher Education. 
Hume, Kenneth I., Mark Brink, and Mathias Basner. 2012. "Effects of Environmental Noise on Sleep." Noise and Health 14 (61): 297. https://doi.org/10.4103/14631741.104897

ISO. 2014. 12913-1: 2014. Acoustics-Soundscape-Part 1: Definition and Conceptual

Framework. Geneva: International Organization for Standardization.

Kang, Jian. 2006. Urban Sound Environment. Boca Raton: CRC Press.

Kang, Jian, Francesco Aletta, Truls Gjestland, Lex Brown, Dick Botteldooren, Brigitte Schulte-Fortkamp, Peter Lercher, Irene van Kamp, Klaus Genuit, and André Fiebig. 2016. "Ten Questions on the Soundscapes of the Built Environment." Building and Environment 108: 284-94. https://doi.org/10.1016/j.buildenv.2016.08.011

Kropp, Wolfgang, Jens Forssén, and Laura Estévez-Mauriz. 2016. Urban Sound

Planning: The Sonorus Project. Gothenburg: Chalmers University of Technology, Division of Applied Acoustics.

Lavia, Lisa, Harry Witchel, Jian Kang, and Francesco Aletta. 2016. “A Preliminary Soundscape Management Model for Added Sound in Public Spaces to Discourage Anti-Social and Support pro-Social Effects on Public Behaviour.” In Proceedings of DAGA, 2016. Aachen, Germany.

Lindqvist, Sven, and Jan Mattsson. 1989. "Planning-topography and Climate: Local Climate Maps for Planning Activities, Including Definitions in These Surveying Techniques." Building Research and Practice 17 (5): 299-304. https://doi.org/10.1080/01823328908726991

Lusk, Katharine. 2018. "Lessons Learned in Effective Community-University-Industry Collaboration Models for Smart and Connected Communities Research." Accessed 10 October 2019. https://hdl.handle.net/2144/35657

McEvoy, Sadie, Frans van de Ven, Michiel Blind, and Jill Slinger. 2018. "Planning Support Tools and Their Effects in Participatory Urban Adaptation Workshops.” Journal of Environmental Management 207 (February): 319-33. https://doi.org/10.1016/j.jenvman.2017.10.041

Payne, Sarah, William Davies, and Mags Adams. 2009. "Research into the Practical and Policy Applications of Soundscape Concepts and Techniques in Urban Areas.” London: HMSO, Department for Environment, Food, and Rural Affairs. 
Payne, Sarah, and Catherine Guastavino. 2013. "Measuring the Perceived

Restorativeness of Soundscapes : Is It about the Sounds, the Person, or the Environment?” In Proceedings of Internoise 2013. Innsbruck, Austria.

Pijpers-van Esch, Marjolein. 2015. "Designing the Urban Microclimate: A Framework for a Design-Decision Tool for the Dissemination of Knowledge on the Urban Microclimate to the Urban Design Process.” PhD diss., Delft University of Technology.

Raimbault, Manon, and Danièle Dubois. 2005. "Urban Soundscapes: Experiences and Knowledge." Cities 22 (5): 339-50. https://doi.org/10.1016/j.cities.2005.05.003

Schulte-Fortkamp, Brigitte, and Kay Voigt. 2012. "Why Soundscape? The New Approach to 'Measure' Quality of Life.” The Journal of the Acoustical Society of America 131 (4): 3437-3437. https://doi.org/10.1121/1.4708894

Stansfeld, Stephen A., and Mark P. Matheson. 2003. "Noise Pollution: Non-Auditory Effects on Health.” British Medical Bulletin 68 (1): 243-57. https://doi.org/10.1093/bmb/ldg033

Steele, Daniel. 2018. "Bridging the Gap from Soundscape Research to Urban Planning and Design Practice: How Do Professionals Conceptualize, Work With, and Seek Information About Sound?” PhD diss., McGill University.

Steele, Daniel, Romain Dumoulin, Christine Kerrigan, and Catherine Guastavino. 2017. "Sounds in the City Workshops: Integrating the Soundscape Approach in Urban Design and Planning Practices." In Proceedings of the AESOP 2017 Conference. Lisbon, Portugal.

Steele, Daniel, Edda Bild, Cynthia Tarlao, and Catherine Guastavino. 2019. "Soundtracking the Public Space: Outcomes of the Musikiosk Soundscape Intervention." International Journal of Environmental Research and Public Health 16 (10): 1865. https://doi.org/10.3390/ijerph16101865

Taylor, Elizabeth Jean, and Joe Hurley. 2016. "“Not a Lot of People Read the Stuff”: Australian Urban Research in Planning Practice.” Urban Policy and Research 34 (2): 116-131. https://doi.org/10.1080/08111146.2014.994741

WHO Regional Office for Europe. 2009. Night Noise Guidelines for Europe. Geneva: World Health Organization. Accessed 10 October 2019. http://www.euro.who.int/en/health-topics/environment-andhealth/noise/policy/who-night-noise-guidelines-for-europe 
Xiao, Jieling, Lisa Lavia, and Jian Kang. 2018. "Towards an Agile Participatory Urban Soundscape Planning Framework." Journal of Environmental Planning and Management 61 (4): 677-98. https://doi.org/10.1080/09640568.2017.1331843 